\title{
60 ANOS DA PRIMEIRA GRANDE OBRA “CONTRA AS SECAS” NO ESTADO DA BAHIA: AÇUDE PÚBLICO JACURICI
}

João Fernando Souza Lima

Universidade Federal da Bahia - UFBA Instituto de Geociências, Salvador, BA, Brasil

jf.desouza@hotmail.com

Noeli Pertile
Universidade Federal da Bahia - UFBA
Instituto de Geociências, Pós-Graduação em Geografia, Salvador, BA, Brasil
noeli.pertile@yahoo.com.br

\begin{abstract}
RESUMO
O presente trabalho tem por objetivo analisar o processo de implantação do Açude Público Jacurici no município de Itiúba, que representou a primeira grande intervenção do governo federal no estado da Bahia, sob o contexto das "obras contra as secas". Executada pelo Departamento Nacional de Obras Contra as Secas (DNOCS) no período 1948-1958, a implantação do referido açude resultou em grandes repercussões socioespaciais e importantes alterações na paisagem do município, entre as quais, a formação do povoado Rômulo Campos, originado em função das obras de construção da barragem. Para esta analise, será feita uma contextualização histórica da problemática da seca, em seus diferentes aspectos, bem como das políticas voltadas para a região do semiárido do Nordeste, durante o século XX. Para obtenção das informações que serão apresentadas, além de uma extensa pesquisa bibliográfica, foi realizado Trabalho de Campo com o objetivo de entrevistar antigos moradores do local e outros agentes envolvidos. Os resultados desta pesquisa revelaram os impactos derivados desta grande intervenção, bem como a importância do açude para a população beneficiada; além do abandono do projeto de irrigação criado na década de 1970 para o fortalecimento da economia do município.
\end{abstract}

Palavras-chaves: Itiúba. Jacurici. Nordeste. Semiárido. Secas.

\section{YEARS OF THE FIRST "DRY AGAINST DRUGS" WORK IN THE STATE OF BAHIA: PUBLIC AUCTION JACURICI}

\begin{abstract}
The present work aimis to analyzing the process of implantation of Public Weir Jacurici in the municipality of Itiúba, which represented the first major intervention of the federal government in the state of Bahia and in the context of "works against droughts". Performed by the National Departament of Works against Droughts (DNOCS) in the period 1948-1958, the implantation of this weir resulted in large socio-spatial repercussions and important changes in the landscape of the municipality, among which, the formation of the village of Rômulo Campos, which originated due to Works of the dam. For this analysis, it will be made a historical contextualization of the problem of drought, in its different aspects, as well as of the policies directed towards the semi - arid region of the Northeast during the Twentieth century. To obtain the information that will be presented, in addition to an extensive bibliographical research, Fieldwork was carried out with the objective of interviewing former residents of the site and other agents involved. The results of this research revealed the impacts derived from this great intervention, as well as the importance of the weir for the benefited population; besides the abandonment of the irrigation project created in the 1970 to strengthen the municipality's economy.
\end{abstract}

Keywords: Itiúba. Jacurici. Northeast. Semi-arid. Dried. 


\section{INTRODUÇÃO}

O clima semiárido do interior da região Nordeste é um fenômeno natural muito particular, considerando que a maior parte do território brasileiro encontra-se dispostos em "um continente dotado de grandes e continuas extensões de terras úmidas" (AB' SABER, 2003, p. 83). As médias pluviométricas anuais dessa região são de $800 \mathrm{~mm}$, sendo que existem áreas inseridas no chamado "polígono da secas" que apresentam médias anuais não maiores que $300 \mathrm{~mm}$. Um grande contraste quando se compara, por exemplo, a áreas da região Norte do país que chegam apresentar médias pluviométricas anuais de até $3.000 \mathrm{~mm}$. De acordo com a Superintendência de Desenvolvimento do Nordeste (SUDENE), a região do semiárido compreende $11 \%$ do território nacional e, conforme a última atualização, do leste do estado do Maranhão ao norte de Minas Gerais, são 1.262 municípios sobre os efeitos desse clima (SUDENE, 2017).

Em razão de ser o clima, um fenômeno natural que sofre influência dos mais diversos fatores, explicar as causas de um clima semiárido sobre $11 \%$ de um território situado na zona climática terrestre caracterizada por altas temperaturas e bastante umidade, não se constitui tarefa fácil. São muitas as teorias que apontam para diferentes fatores de influência, entre os quais, as barreiras físicas das chapadas da Borborema e Diamantina que, supostamente, impediriam a penetração de massas de ar úmidas pelo interior da região. Nimer (1989) é quem apresenta uma explicação de melhor compreensão para o fenômeno. Segundo este autor, a área que compreende o semiárido encontra-se sob o domínio do centro de ação do Atlântico que impede o deslocamento para o sul da Frente Intertropical (FIT), situada próximo ao Equador e responsável por aguaceiros e trovoadas. Por essa razão, o período chuvoso do semiárido se concentra entre janeiro e abril, quando o centro de ação se afasta permitindo a aproximação da FIT. Nos anos de secas excepcionais, isso não acontece ficando a região submetida ao longo período de estiagem e a todas as suas consequências.

O que se concebe atualmente é que, conforme Waring (1923), o maior problema do semiárido não está na falta de chuva, mas na sua irregularidade no tempo e no espaço, fenômeno que, associado à estrutura social da região, há séculos, condena milhões de brasileiros a severas calamidades. Tomando como causas do problema o fenômeno climático, o governo federal, desde meados do século XIX, lançou mão de um grande programa de construção de barragens em toda região, visando aumentar a disponibilidade hídrica (CARVALHO, 1987). Esse programa ficou conhecido como a política da "açudagem" e pontilhou todo o semiárido com inúmeros reservatórios artificiais (BEZERRA, 1996).

Foi nesse contexto que a região do semiárido do estado da Bahia recebeu a implantação de um grande reservatório artificial, o Açude Público Jacurici. O município escolhido para essa primeira grande intervenção do governo federal no estado foi Itiúba, situado na microrregião de Senhor do Bonfim, região norte da Bahia, inserido entre os paralelos $10^{\circ} 25^{\prime} 12^{\prime \prime}$ e $10^{\circ} 57^{\prime} 56^{\prime \prime}$ de latitude sul e os meridianos $39^{\circ} 37^{\prime} 27^{\prime \prime}$ e $40^{\circ} 3^{\prime} 32^{\prime \prime}$ de longitude oeste (Figura 1). De acordo com o IBGE (2010), Itiúba está distante da capital 377 km, possui 36 mil habitantes distribuídos por uma área de $1.722 \mathrm{~km}^{2}$. Segundo dados da Superintendência de Estudos Sociais e Econômicos da Bahia (SEI), a principal fonte de receita do município provém dos setores da Administração Pública, Seguro Social, seguido do setor de Comércio e Serviços, conjunto que representa $81 \%$ do total do Produto Interno Bruto (PIB) do município.

Considerando a relevância das ações do Estado para a convivência do homem com o clima semiárido e de todas as repercussões socioespaciais resultantes dessas ações, o presente estudo busca problematizar a respeito da importância, dos impactos e da situação atual do uso econômico da água do Açude Público Jacurici no município de Itiúba. Nesse sentido, levantase as seguintes questões: como se realizou o processo de implantação do Açude Público Jacurici no município de Itiúba e quais foram os efeitos resultantes desse processo? Qual é a importância atual do Perímetro Irrigado Jacurici criado com vistas ao fortalecimento da economia e desenvolvimento socioeconômico do município?

Levando em conta que as intervenções do Estado para região do semiárido do Nordeste possuem o caráter de políticas territoriais, torna-se imprescindível, aqui, suscitar o conceito de território, uma das categorias mais importantes da Geografia. Destarte, observa-se que é consensual a inseparabilidade entre o conceito de território e a ideia de poder. De acordo com Andrade (2004), a expressão "território" é de uso antigo tanto nas ciências naturais quanto nas

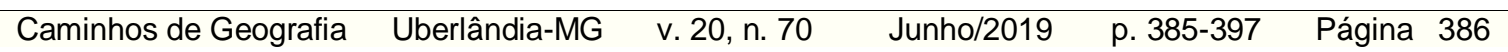


ciências sociais e atualmente sofre grande concorrência com termos tradicionais como "espaço" e "região". Ao afirmar que nas ciências naturais o território seria a área de influência e predomínio de uma espécie animal que exerce o domínio dela, o autor deixa evidente a ideia de controle, de poder. Por outro lado,]

[...] Em ciências sociais a expressão território vem sendo muito utilizada desde o século passado por geógrafos como Frederico Ratzel, preocupado com o papel desempenhado pelo Estado no controle do território e também por Élisée Reclus que procurava estabelecer a relações entre classes sociais e o espaço ocupado e dominado [...]. (ANDRADE, 2004 p. 19).

Andrade (2004) reforça que o conceito de território está muito ligado a ideia de domínio e de poder ou de gestão de determinada área, não devendo este ser confundido com os conceitos de lugar e de região, por exemplo. Concordante com esse autor está Souza (2011), ao afirmar que o uso indistintamente dos temos "território" e "espaço" obscurece o caráter especificamente político do primeiro. E embora as políticas territoriais, analisadas no presente trabalho, sejam referentes ao poder do Estado, o referido autor advoga que o conceito de território deve ir além do poder que emana do Estado-Nação, abarcando outra formas de territorialidade como, por exemplo, uma determinada área de uma cidade dominada por facções criminosas rivais ou uma praça disputada por profissionais do sexo. Por tanto, o autor assinala que "todo espaço definido e delimitado por e a partir de relações de poder é um território, do quarteirão aterrorizado por gangues de jovens até o bloco constituído pelos países-membros da OTAN" (SOUZA, 2011, p.111).

Nesse sentido, conforme os conceitos apresentados pelos dois autores citados, onde houver relações de poder manifestando-se sobre um substrato referencial definido, pressupõe-se a existência de um território.

Figura 1 - Mapa da área de estudos.

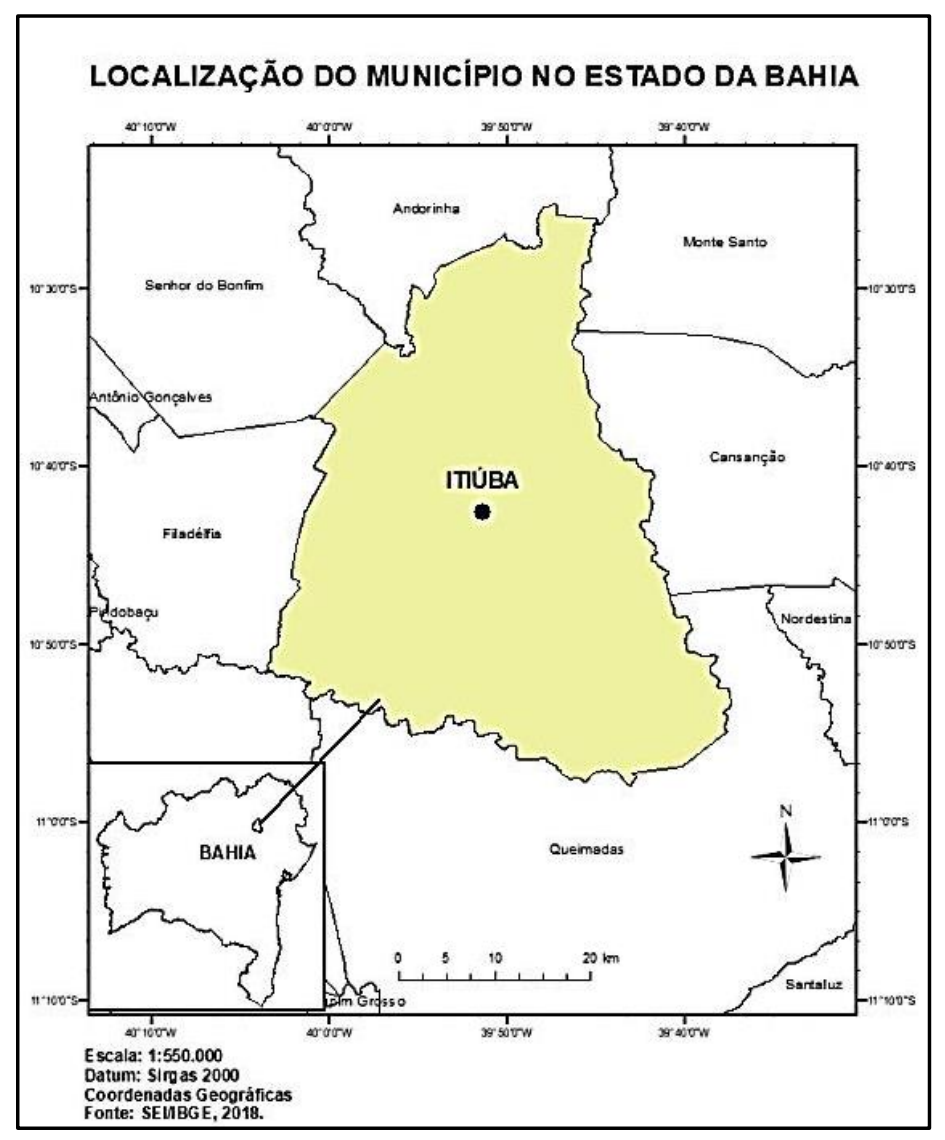


Na próxima seção deste trabalho será feita uma análise das secas históricas que marcaram a região do semiárido do Nordeste e justificaram as primeiras ações do Estado brasileiro para o enfrentamento aos efeitos do fenômeno, contexto no qual foi criado o Departamento Nacional de Obras Contra as Secas (DNOCS). Na terceira seção será tratada a primeira grande intervenção do governo federal no estado da Bahia com a implantação do Açude Público Jacurici, no município de Itiúba, e as repercussões socioespaciais decorrentes desta intervenção. A quarta seção faz uma análise das políticas de desenvolvimento para o semiárido, pautadas no uso econômico das águas represadas para grandes projetos de irrigação. A última seção analisa o histórico do Perímetro Irrigado Jacurici, implantado no referido município no contexto das políticas de desenvolvimento para o Nordeste.

Cabe destacar que este artigo constitui parte da pesquisa realizada por um dos autores para seu Trabalho de Conclusão de Curso de Graduação em Geografia (Bacharelado) da Universidade Federal da Bahia (UFBA), defendido no mês de fevereiro de 2018, sob orientação da segunda autora.

\section{AS SECAS HISTÓRICAS E A INTERVENÇÃO DO ESTADO: A “AÇUDAGEM”}

Foram as grandes secas históricas dos séculos XIX e XX que justificaram as primeiras ações do Estado brasileiro para o enfrentamento do problema na região do semiárido. A primeira grande seca deste período, de efeitos catastróficos para a população daquela região, ocorreu no biênio 1877-1879, quando cerca de 500 mil vidas foram ceifadas pela fome e diversas doenças (GERRA, 1981; ANDRADE, 1985; CARVALHO, 1987; VILLA, 2000). Estima-se que esse número correspondia a $5 \%$ da população brasileira daquele período. Posteriormente a essa grande tragédia, ocorreram mais duas grandes secas no século XX (1915 e 1932) que, assim como a anterior, causou grande calamidade. Um fato comum a essas três grandes secas foi a criação dos chamados "Campos de Concentração". Esses Campos foram áreas criadas para o confinamento dos retirantes das áreas secas que se dirigiam em busca de ajuda para cidades como fortaleza e Crato no Ceará. Nesses confinamentos, segundo Castro (1965) e Rios (2014), a desnutrição e doenças infectocontagiosas, a exemplo de sarampo, varíola e tifo, causaram milhares de óbitos. Ali, tamanho era o desdém dispensado à vida humana que esses "Campos de Concentração" poderiam ter inspirado os Campos de Concentração nazistas da Segunda Guerra Mundial. Aliás, esse foi um dos piores capítulos na história das secas do Nordeste. Talvez por isso mesmo, omitido pela História Oficial e ocultado intencionalmente dos livros didáticos brasileiros.

Antes das ações práticas "contra as secas", o governo imperial já havia tomado algumas medidas de menor impacto visando amenizar o sofrimento da população. Segundo Villa (2000), na década de 1830 foram abertos poços e cacimbas, construídos pequenos açudes e estradas. Em 1856 foi criada a Comissão Científica de Exploração com o objetivo de estudar a ecologia da região do semiárido e propor ações amenizadoras para os longos períodos secos. Ao final dos estudos, essa Comissão recomendou a melhoria do sistema de transportes, construção de açudes, instalação de estações meteorológicas e a transposição do Rio São Francisco (MELLO, 2011).

Mas só depois da seca histórica do biênio 1877-1879, foi iniciada uma política de construção de açudes por toda região das secas. Era a tentativa de resolver o problema por meio de soluções hidráulicas, política que ficou conhecida como "açudagem" (CARVALHO, 1987). Desta forma, o açude de Cedro, construído no município de Quixadá (CE), foi a primeira grande obra deste período. O reservatório tinha capacidade de armazenamento para 125 milhões de $\mathrm{m}^{3}$ e sua construção durou 16 anos (1890-1906). Para a execução da açudagem, o governo federal criou, em 1909, a Inspetoria de Obras Contra as Secas (IOCS) que, em 1945, passou a se chamar Departamento de Obras Contra as Secas (DNOCS), denominação atual. A criação deste órgão tornou-se um marco na história das secas do Nordeste, simbolizando o início de importantes alterações na paisagem da região. Pois, ao longo de todo século XX surgiram no semiárido imensos espelhos d'águas em bacias de rios intermitentes. Conforme aponta Bezerra (1996), neste período foram construídos 70 mil açudes em toda região. Tornase indispensável lembrar que a política da "açudagem" teve seu ápice em meados do século XX, sendo a década de 1950 o período no qual mais se iniciou e concluiu obras de barragens, conforme apontado na figura 2. 
Figura 2 - Semiárido Brasileiro: açudagem no século XX.

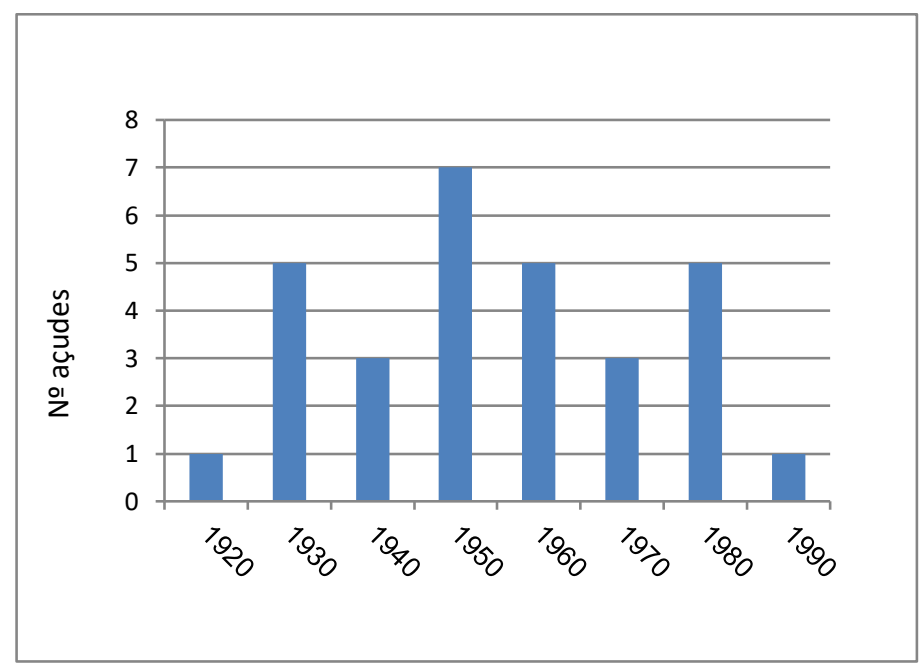

Fonte - DNOCS, 2017a.

Esses acontecimentos marcaram, inclusive, a cultura da região. Tanto na música como na literatura, surgiram manifestações que remontam o cenário daquele período. Luiz Gonzaga, por exemplo, em uma de suas interpretações, "Vozes da Seca" de 1953, pede pela "açudagem" e pelos empregos nas frentes de trabalho, criadas pelo governo para ocupar a mão de obra ociosa dos atingidos pelas secas. Um trecho da letra diz: "Dê serviço a nosso povo, encha os rios de barragem / Dê comida a preço bom, não esqueça a açudagem" (composição com Zé Dantas - José de Souza Dantas Filho). A escritora Raquel Queiroz em "O quinze", por meio de seus personagens retrata o sofrimento do povo no deslocamento do interior para as cidades e os horrores dos "Campos de Concentração". Em um dos trechos da obra lê-se:

\begin{abstract}
Conceição atravessava muito depressa o Campo de Concentração [...]. Ela tirava um níquel da bolsa e passava adiante, em passo ligeiro, fugindo da promiscuidade e do mau cheiro do acampamento [...]. Que custo, atravessar aquele atravancamento de gente imunda, de latas velhas, e trapos sujos! (QUEIROZ, 1977, p. 40)
\end{abstract}

A narrativa descreve a passagem da personagem Conceição em frente a um dos "Campos de Concentração" de Fortaleza (CE), quando se deslocava para sua residência. Outros autores da literatura brasileira também trouxeram em suas obras o drama social da região do semiárido do Nordeste, a exemplo de: José de Alencar com "O Sertanejo" (1875); Euclides da Cunha com "Os Sertões" (1902) e Graciliano Ramos com "Vidas secas" (1938).

\title{
O AÇUDE PÚBLICO JACURICI NO CONTEXTO DAS OBRAS CONTRA AS SECAS
}

Foi no auge da política da "açudagem" que o município de Itiúba recebeu no ano 1958 uma das grandes "obras contra as secas", o Açude Público Jacurici, que em 2018 está completando 60 anos da conclusão de sua barragem. Esta obra representa a primeira intervenção de grandes proporções realizada pelo governo federal no estado da Bahia. Na categoria "açude", o Jacurici se configura como o segundo maior do estado em capacidade de armazenamento (146 milhões de $\mathrm{m}^{3}$ ), sendo o açude de Cocorobó, no município de Canudos, o de maior capacidade (246 milhões de $\mathrm{m}^{3}$ ), segundo DNOCS (2017b).

O Jacurici foi formado pelo barramento do rio de mesmo nome a $78 \mathrm{~km}$ de sua nascente e a 32 $\mathrm{km}$ de sua confluência com rio Itapicuru e é um dos principais afluentes deste (DNOCS, 2017c). Sua construção, que teve administração direta do DNOCS, durou 10 anos (1948-1958) e resultou em importantes alterações na paisagem da zona rural de Itiúba. A mais importante dessas alterações, refere-se à formação do povoado de Rômulo Campos, nome dado em homenagem ao engenheiro do corpo técnico do DNOCS, responsável pela realização obra (AZEREDO,1987). O referido povoado surgiu a partir de uma pequena feira, criada para vender produtos aos operários da construção.

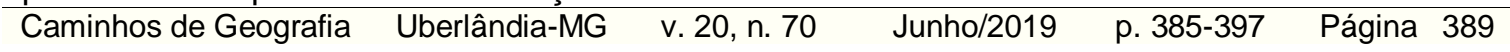


Atualmente Rômulo Campos é o povoado economicamente mais importante do município e o de maior população que, segundo o IBGE (2010) conta com 2.577 habitantes. Parte da população pleiteia sua emancipação, desejo que esbarra na legislação atual a qual estabelece, entre outros critérios, população mínima de 12.500 habitantes para aqueles municípios pertencentes à região Nordeste (BRASIL, 2015).

"No antigo Deserto da Camandaroba, surgiu um oásis. A abundância substituiu a fome de uma região. Houve um milagre!" Assim, Azerêdo (1987, p. 167) descreve a implantação do Açude Público Jacurici no povoado de Rômulo Campos, também conhecido como Camaleão e Camandaroba. $\mathrm{O}$ entusiasmo do autor se justifica, principalmente, pela maior disponibilidade de água com a qual a população do município passou a contar. Nesse sentido, o açude levou grande alívio para a população, mas especialmente para aqueles moradores daquela área da zona rural, já que habitantes da sede dispunham de outras fontes de abastecimento. Uma antiga moradora do local revela em entrevista realizada durante o Trabalho de Campo como era as condições de acesso a água antes do açude:

\begin{abstract}
Meu filho, quem tem uma felicidade dessa, comparando aos tempos que a gente vivia era de cacimba, bebendo água onde adivinhava que não era salgada. Aquela cacimba que era de água doce, oito dias depois era preciso cavar em outro lugar porque aquela já estava salgada. Por que é que ninguém quer que volte aquele tempo? Se voltar, morre todo mundo. (S. M., MORADORA DE RÔMULO CAMPOS, Trabalho de Campo, 2017).
\end{abstract}

A obra de construção da barragem do açude atraiu um grande contingente para o local, fato que contribuiu decisivamente para a formação de Romulo Campos. Nesse sentido, pode-se afirmar que o povoado surgiu e cresceu em função das atividades para implantação do reservatório. O Sr. J. C. (84 anos) é aposentado do DNOCS e foi um dos operários da construção. Começou a trabalhar quando tinha, ainda, 16 anos. $O$ aposentado revela como se deu o início do povoamento de Rômulo Campos:

Era uma casa de roça, uma fazenda. Era um mato danando. Dalí foram se aproximar o empregado que fazia uma barraca, foi crescendo, no fim já tinha algumas casas. A feira era lá na frente do portãozinho do DNOCS. Era uma feira muito boa. Corria dinheiro, né? Onde corre dinheiro... [...] (J. C., FUNCIONÁRIO APOSENTADO DO DNOCS, Trabalho de Campo, 2017).

E nesse contexto, alguns problemas foram verificados durante os anos de atividade. As condições de insalubridade era um desses problemas. Os operários trabalhavam, muitas vezes, a noite e sob chuva, condições que levavam muitos a adoecerem. A contratação de menores de idade era algo comum. Essa situação foi observada por Villa (2000) e, segundo este autor, já ocorria nos trabalhos de construção de açudes na década de 1930:

As condições de trabalho eram péssimas, segundo o próprio inspetor. Só no açude de Lima Campos, estavam instaladas 75 mil pessoas e faltava de tudo: ferramentas, pessoal técnico, material de construção e transporte. [...] Os trabalhadores, segundo o inspetor, foram colocados em um curral, onde conviviam homens, mulheres, crianças e idosos. Os menores de idade representavam $15 \%$ dos trabalhadores, a maioria formada por órfãos [...] (VILLA, 2000, p. 157).

Atraso de salários e baixa remuneração era outro problema comum no canteiro da construção. O morador de Rômulo Campos C. M. (83 anos) conta que trabalhou na construção por três anos, mas devido ao valor recebido de $15 \mathrm{mil}$ Reis por mês, correspondente a $\$ 7,37$ (sete dólares e 37 centavos) em valores atuais (FEE, 2017), passava muita fome. Essa situação o fez pedir demissão e migrar para o estado de Goiás, onde foi trabalhar em uma fazenda recebendo $15 \mathrm{mil}$ Reis por dia, com alimentação e alojamento por conta do empregador. $O$ morador justifica os motivos que o levaram a não trabalhar por muito tempo na obra do DNOCS:

Trabalhei por 3 anos, mas era uma fome danada. Tinha os barracões que você comprava meio quilo de carne para passar a semana, aí eu disse: quer 
saber? Eu vou pedir minas contas. Pedi mais o Valdo do Argemiro (outro operário da obra) que morava na mata e se mandamos pelo mundo. Fomos bater em Goiás. Chegamos lá, fomos trabalhar em uma fazenda. Aqui a gente ganhava 15 Mil Réis por mês e lá a gente ganhava 15 Mil Réis por dia à custa da casa (C. M., MORADOR DE RÔMULO CAMPOS, 2017).

O valor de 7,37 dólares corresponde atualmente a um valor aproximado de 23 Reais (BANCO CENTRAL DO BRASIL, 2017). Esse era o valor pago por cada mês de trabalho e só recebido a cada 90 dias. Já os barracões, citados pelo morador, era outro fator de descontentamento. Tratava-se, na verdade, de casas comerciais montadas por fazendeiros, líder políticos locais para vender produtos aos operários da obra que eram, praticamente, obrigados a comprar nessas casas. Compravam fiado e tinham o produto discriminado em cadernetas de débito. $\mathrm{Na}$ data do pagamento, os comerciantes dirigiam-se ao escritório do DNOCS apresentando o nome dos devedores e os produtos adquiridos nos barracões, depois de definido os preços, o pagamento do débito era feito primeiro a esses comerciantes, tocando para os operários apenas o valor restante da quitação das dívidas. J. C (84 anos), funcionário aposentado do órgão federal explica como tudo funcionava:

Era uma casa comercial que vendia farinha, feijão, carne e até tecido eles
tinham. Naquele tempo não se comprava roupa pronta. O DNOCS garantia o
pagamento. No final do mês o fornecedor, de posse das anotações das
compras já somadas em uma caderneta com o nome dos devedores, se
dirigia ao escritório onde era realizado o pagamento e saia de lá já com o
dinheiro. Era muito bom. O dono do barracão recebia primeiro do que o dono
do dinheiro. Era assim que funcionava. (J. C., FUNCIONÁRIO
APOSENTADO DO DNOCS, Trabalho de Campo, 2017).

O fato descrito revela a apropriação do órgão federal pelos grupos dominantes em detrimento de uma parcela considerável de oprimidos. Essas relações promíscuas, infelizmente, permeiam a história do DNOCS desde sua criação. A apropriação do órgão por forças políticas regionais e por poderosos locais, beneficiários da chamada "indústria da seca", contribuiu para o agravamento do problema de caráter político-social que se constitui a seca. Esses grupos, de um modo ou de outro, buscavam levar vantagem da situação e, assim, perpetuar a estrutura social que Ihes favorecia. É devido a essa realidade que, de acordo com Andrade (1985, p. 29), "o sertanejo costuma afirmar que a seca é a madrasta do pobre e a mãe carinhosa dos ricos". Deste modo, pode-se constatar que a seca era - e ainda é - um grande e próspero negócio para muita gente (FURTADO, 1989).

É por essa e por tantas outras razões que as análises feitas por alguns autores a respeito da política da "açudagem", como forma de intervenção do Estado na região do semiárido do Nordeste, concluem que, no que se refere à mudança do quadro social da região, quase nada foi feito. Isso porque, as mudanças desejadas e necessárias culminariam na perda de privilégios dos grupos políticos dominantes do Nordeste. Por isso, torna-se importante não confundir tais ações do Estado para o enfrentamento aos efeitos da seca com política de planejamento regional, visando alteração no quadro da estrutura social. Bezerra (1996), por exemplo, afirma que a intervenção do Estado no combate às secas representou a primeira manifestação do planejamento da atividade governamental na tentativa de solucionar o problema. Contudo, Carvalho (1987), que analisou de forma detalhada esse contexto histórico, afirma que as ações do Estado, baseada no represamento de água, apenas reforçaram a dominação e o poder de certos segmentos, ampliando a injusta realidade social. Diz a autora sobre as intervenções:

Como se sabe, essas práticas não se traduziram na resolução, atenuação ou sequer em melhor entendimento dos problemas dessa área. Capturados pelas oligarquias nordestinas, os organismos encarregados do tratamento desses problemas passaram a atuar fundamentalmente em benefício daqueles segmentos, mantendo e reforçando (ao invés de transformar) a configuração da realidade social da região (CARVALHO, 1987, p. 46). 
Um dos organismos capturados pelas oligarquias, citado pela autora, é exatamente o DNOCS que, de diversos modos e diversas frentes, viabilizava a transferência de recursos do Estado para as mãos dessas oligarquias.

Sobre esse tema Oliveira (1977, p. 51) observa que, apesar de quase existir um consenso sobre o planejamento estatal no combate às secas, "seria apressado demais, porém, e cientificamente leviano afirmar que a IFOCS, e posteriormente o DNOCS, representou algo parecido com planejamento" e que na época da criação desse órgão sequer havia uma teoria do planejamento. Referindo-se aos avanços do DNOCS, o autor observa, ainda, que não houve avanços; mas sim em termos de entendimento e desvendamento de sua estrutura socioeconômica.

Nesse sentido, Carvalho (1987) vai além ao afirmar que as intervenções, não apenas mantiveram o quadro existente como acentuaram as desigualdades sociais e explica os motivos:

O represamento não levou a uma melhor utilização da água. As barragens, açudes e poços não tinham um caráter publico, e nunca se cuidou de uma desapropriação de terras em volta deles para melhor utilização agrícola da água, armazenada em grande quantidade, mas intensamente subutilizada. As obras de busca ou acumulação de água se concentraram nas propriedades privadas dos médios ou grandes fazendeiros (CARVALHO, 1987, p. 46).

Esses autores, porém, concordam que as práticas para o planejamento regional só vieram acontecer, de fato, entre as décadas de 1950 e 1960, com a mudança de paradigma, quando se abandonou o paradigma de "combate às secas" para seguir o paradigma da "convivência com a seca", mudança, aliás, que, segundo Pomponet (2009), desloca a questão da abordagem climática para a dimensão econômica e social.

\section{O USO ECONÔMICO DAS ÁGUAS E O HISTÓRICO DO PERÍMETRO IRRIGADO JACURICI}

Em meados do século passado os açudes construídos pelo DNOCS já acumulavam sete bilhões de $\mathrm{m}^{3}$ de água (FURTADO, 1989). Esse quadro, aparentemente otimista, foi resultado da política de "açudagem" que apostava na "solução hidráulica" como redenção da população da região do semiárido. Água, então e em tese, não era mais problema. Contudo, as secas sucessivas que se abatiam na região continuavam a fazer vítimas sertão a fora. Essa situação social colocava o Nordeste como a região mais subdesenvolvida entre as regiões brasileiras, justo no momento em que o Centro-sul gozava de bons indicadores econômicos, consequência de um salto industrial que sucedeu o ciclo econômico do café. Percebeu-se, então, que se fazia necessário identificar as causas de tamanha disparidade e atacá-las na sua origem, promovendo desenvolvimento para a região, buscando alternativas que pudessem melhorar a vida de uma população que há séculos estivera oprimida pela estrutura social dominante, situação agravada a cada seca periódica que acontecia.

Norteado por foi com esse objetivo e contra a vontade das lideranças políticas conservadoras da região, que em 1959 foi criada pela lei federal no 3.692 a SUDENE. Norteada por propostas de desenvolvimento e gestão do território, essa agência tinha como objetivo identificar os principais problemas da região e criar políticas que pudessem fomentar o seu desenvolvimento econômico, alterando, assim, o quadro social desigual. Teve na sua direção, o economista paraibano Celso Furtado que enxergava na estrutura fundiária o maior problema do Nordeste.

As ações para o desenvolvimento do Nordeste, propostas pela SUDENE, visavam intervenções em diversos campos e formavam um grande conjunto. Citando algumas: melhoramento da estrutura rodoviária; incentivos à industrialização; expansão da eletrificação rural; investimento na formação de uma mão de obra técnica da própria região; construção de estrutura para armazenar alimentos para o consumo nos tempos críticos de seca e desenvolver a agricultura de subsistência aproveitando a estrutura hidráulica existente para produção irrigada com as águas dos açudes construídos pelo DNOCS (FURTADO, 1989). Pois, até o período de 1950, o DNOCS havia se limitado a construção de açudes e barragens para beneficiar prioritariamente a pecuária, desprezando outros usos e, assim, subaproveitando uma imensa massa d'água. Realidade contraditória, pois, conforme observa Pébayle (1981, apud BURSZTYN 1984, p.80), 
a região Nordeste já era, naquele período, o espaço semiárido mais bem servido de água represada do mundo e o menos irrigado. Por essa razão, as secas ocorridas após esse período continuaram a trazer dificuldades para o sertanejo do semiárido, mesmo depois de um grande volume hídrico acumulado nos reservatórios da região.

Desta forma, a irrigação era a grande aposta para o fortalecimento da economia da região do Semiárido. Por isso, em 1968 foi criado o Grupo Executivo para Irrigação e Desenvolvimento Agrícola (GEIDA). Em 1971 este grupo apresentou o Programa Plurianual de Irrigação (PPI) contendo ações para a região Nordeste, contemplada com $85 \%$ dos projetos, conforme apontam Evangelista e Vidal (2012). De acordo com esses autores o PPI previa 36 projetos de irrigação administrados pelo DNOCS, priorizando os vales úmidos do polígono das secas. Este programa, na sua primeira etapa, pretendia irrigar 40 mil hectares (GOMES, 1979).

No estado da Bahia três bacias foram contempladas no Programa Plurianual de Irrigação: Bacia do Rio de Contas na região sudoeste; Bacia do Vaza-Barrís e Bacia do Itapicuru, ambas situadas na região norte do estado. Cada uma dessas bacias recebeu um perímetro irrigado. Esses perímetros foram instrumentos criados para atingir os objetivos do PPI, fomentando a formação de grupos produtores, selecionados e orientados tecnicamente pelo DNOCS (BURSZTYN 1984). O sistema praticado por esse programa consistia no "colonato", ou seja, o produtor e sua família moravam no próprio lote onde trabalhavam atendidos por serviços básicos como postos de saúde e escolas mantidos pelo órgão federal. Nesse sentido, as atribuições do órgão federal foram redefinidas, passando de mero realizador de obras de infraestrutura a fomentador do processo de desenvolvimento regional.

\section{O PERÍMETRO IRRIGADO JACURICI: INÍCIO, MEIO E FIM.}

Foi no contexto da política de projetos de irrigação que em 1973 o povoado de Rômulo Campos recebeu a implantação do Perímetro Irrigado Jacurci, instalado a jusante da barragem do reservatório. De acordo com o DNOCS (2017d), para a implantação desse projeto foi desapropriada uma área de 1.100 hectares e distribuídos 161 hectares a 36 famílias de pequenos produtores. Cada irrigante recebia um lote de 2,2 hectares. O processo de seleção das famílias que recebiam os lotes irrigados obedecia a determinados critérios estabelecidos pelo DNOCS, entre eles: idade máxima de 45 anos; casado, ter dois filhos, no mínimo; não ser analfabeto; dedicação exclusiva e conhecimento na agricultura.

O perímetro irrigado representou grande importância socioeconômica para o município de Itiúba. Pois, no período do seu pleno funcionamento a produção de gêneros alimentícios proporcionou melhores condições de vida para as famílias envolvidas no projeto, dinamizando também a economia local. A produção de alimentos no perímetro era bastante diversificada. Os irrigantes produziam melancia, milho, quiabo, limão, feijão, arroz, banana, tomate, pepino, melão, repolho, mamona, pimentão, coco da Bahia e hortaliças, produção que era destinada ao consumo local.

O morador de Rômulo Campos, Sr. C. S. (68 anos), foi presidente por oito anos de uma das duas cooperativas criadas pelos grupos de trabalhadores sob orientação do DNOCS. C. S. afirma que a produção de tomate, em determinado período, foi o carro chefe da produção, chegando a 139 toneladas. $O$ arroz também foi um produto de destaque chegando a 16 toneladas na década de 1980. Um levantamento do Centro de Planejamento e Estudos do Estado da Bahia (CPE) realizado em 1982, nas áreas de irrigação do estado, concluiu que a produtividade média do arroz no Perímetro Irrigado Jacurici era de 4.700 toneladas por hectare e que a área produzida era de 21 hectares. Além desses dois produtos de destaque, entre as décadas de 80 e 90 foi incentivada a produção de sementes de melancia e abóbora destinada a uma empresa estrangeira. Essa atividade passou a ser, na ocasião, uma atividade promissora, como observou Barros e Senna $(1989$, p. 65) ao verificar que "[...] a produção de sementes fiscalizadas ganhou grande impulso, pelo seu efeito multiplicador e já é grande posto de venda para os irrigantes do Perímetro Irrigado Jacurici, na Bahia".

Toda essa situação favorável gerou bons resultados, fazendo, até mesmo, surgir uma nova classe social no município de Itiúba: Os colonos. Nos tempos de intensa atividade econômica, morar nos "Colonos" - termo até hoje utilizado para se referir tanto ao núcleo habitacional do perímetro quanto aos irrigantes - era sinônimo de boa condição financeira. O Sr. O. B. (72 
anos), funcionário aposentado do DNOCS, acompanhou de perto a trajetória dos irrigantes e relembra a boa situação de quem vivia e trabalhava no perímetro: "Os colonos viviam bem, com muitas posses, muita fartura. Assim que começaram a ganhar dinheiro, compraram casa e carro". Situação confirmada pelo "colono" Sr. C. S. ao relatar que foi com o trabalho no perímetro que conseguiu formar todos os seus filhos e comprar uma casa no povoado de Rômulo Campos, realidade alcançada por quase todos envolvidos no projeto.

Contudo, de grande promessa para um desenvolvimento da economia local e alterações no quadro social do município, o projeto do perímetro irrigado passou a um sonho que teve seu começo, meio e seu fim. Tudo que em outro tempo era promessa de prosperidade e riqueza, deu lugar a decadência. A água do açude continuou a cursar pelos canais do perímetro irrigado, mas as cooperativas faliram, os irrigantes se desorganizaram, a produção desapareceu e os colonos descolonizaram a área. A explicação para o fracasso do projeto e 0 abandono das atividades no perímetro irrigado é bastante complexa e essa complexidade é refletida nas diferentes opiniões das pessoas envolvidas nesse contexto, quando tentam explicar os motivos do fim. Consenso entre todos, somente quanto à ocorrência de sucessivas secas entre o final da década de 1980 e meados da década de 1990, que teriam inviabilizado a produção.

Porém, uma análise mais detalhada sobre a questão, leva-se a concluir que o abandono das atividades no Perímetro Irrigado Jacurici, não foi um caso isolado, ocorrendo também em muitos outros projetos de outros estados da região do semiárido. Esse problema foi resultado de uma soma de fatores de ordem política, econômica e social daquele período, associados a particularidades de cada local. Nesse sentido, Mendonça (2010) observa que o declínio dos projetos de irrigação coincidiu com ideias neoliberais que influenciaram o Brasil na década de 1990 as quais defendiam um Estado menos interventor e mais regulador. O autor aponta, ainda, a relação paternalista e autoritária do DNOCS com os "colonos" como outro motivo para o fracasso dos projetos. Bursztyn (1984), por sua vez, afirma que políticas voltadas para os irrigantes tentavam impor a pequenos produtores de cultivos de subsistência, uma visão empresarial, ideia a qual esses não se adaptaram.

Além dos problemas mencionados, a desarticulação entre as três esferas do poder (União, Estados e Municípios) também contribuiu para o desmonte dos projetos. Foi o que concluiu Fernandes et al (2008) no relatório da Del Giudice Acessória Técnica LTDA, empresa contratada pelo Ministério da Integração Nacional no ano de 2007 para fazer um levantamento da situação desses projetos de irrigação e propor novas diretrizes. Segundo esse relatório "a política de desenvolvimento regional no Nordeste brasileiro se estabeleceu de forma equivocada, uma vez que as estratégias não eram articuladas com estados e municípios envolvidos" (FERNANDES et al, 2008, p. 48). Evangelista e Vidal (2012) fizeram interpretação semelhante ao observarem que as ações do governo federal para formulações e implantação de perímetros irrigados, não incluíram estados e municípios no processo decisório nem no planejamento dos projetos e que este aspecto, certamente, contribuiu para o fracasso de muitos projetos públicos de irrigação no Nordeste.

Atualmente, poucos colonos permanecem na área do Perímetro Irrigado Jacurici. A maioria vendeu seus lotes e foi morar na área urbana de Rômulo Campos. Depois que alguns lotes foram ocupados por famílias do Movimento dos Trabalhadores Sem Terra (MST) no início da década de 2000, dois assentamentos foram estabelecidos no local e os assentados produzem, em pequena escala, algumas variedades de hortaliças, legumes, verduras e frutas. O que vem predominando, de fato, nas terras que já produziram um grande volume de alimentos é o capim para produção de Feno (capim desidratado) utilizada tanto para alimentação do gado dos produtores quanto para a comercialização.

\section{CONSIDERAÇÕES FINAIS}

É inegável a importância que representou as intervenções do Estado no semiárido para o enfrentamento aos efeitos da seca durante todo o século XX. O DNOCS representou um importante papel nas obras de represamento de rios, construção de vias de circulação e conhecimento da ecologia da região, desbravando terras quase isoladas. Contudo, torna-se imprescindível observar que essas ações não conseguiram realizar grandes transformações sociais tão esperadas e necessárias, conforme observam autores citados neste trabalho. E

$\begin{array}{lllll}\text { Caminhos de Geografia } & \text { Uberlândia-MG } & \text { v. 20, n. } 70 \quad \text { Junho/2019 } & \text { p. 385-397 } & \text { Página } 394\end{array}$


muito embora não se presencie atualmente o cenário de horror, como consequências dos períodos de seca anormais, ainda hoje, em pleno século XXI, ações paliativas continuam sendo praticadas. A "indústria do carro pipa", por exemplo, segue em marcha firme a favorecer pequenos grupos. A seca, infelizmente, ainda é um perverso cabresto para o homem nordestino do semiárido.

No caso do Açude Público Jacurici, sua implantação, no que se refere disponibilidade hídrica, se tornou um divisor de águas para a população de Itiúba e municípios vizinhos. Atualmente é este reservatório a principal fonte de abastecimento para uma população de quase 40 mil habitantes, do município estudado. Contudo, se fazem urgentes ações que promovam um melhor aproveitamento econômico da água represada, a qual boa parte se perde para evaporação. É preciso estudar a viabilidade de se retomar a produção de alimentos no Perímetro Irrigado Jacurici, tão importante no passado. Se eventualmente algum fator de qualquer natureza indicar pela inviabilidade da irrigação, a exemplo das sucessivas e cada vez mais longas secas, a saída pode ser apostar na reinvenção das funções do açude como a piscicultura superintensiva que já vem sendo praticada no reservatório e desponta como grande promessa econômica no uso de águas represadas do semiárido e de outras regiões do país. Alternativas como esta evidenciam que a região do semiárido é uma terra possível e que, o discurso que atribui ao fenômeno climático a culpa pelo sofrimento de toda uma população, não encontra mais ressonância.

O trabalho aqui apresentado buscou alertar para a importância que representa o Açude Público Jacurici no município de Itiúba, como principal fonte de abastecimento humano e provedor de sustendo para uma população de quase 40 mil habitantes. Espera-se que este estudo possa contribuir para outros trabalhos e para ações de uso consciente da água que vise a proteção do manancial e a garantia do acesso às gerações futuras.

\section{REFERÊNCIAS}

AB'SÁBER, Aziz Nacib. Os Domínios de Natureza do Brasil: potencialidades paisagísticas. São Paulo: Ateliê Editorial, 2003.

ALENCAR, José de. O sertanejo: romance brasileiro. Rio de Janeiro: B. L. Garnier, 1875.

ANDRADE, Manoel Correia de. A seca: realidade e mito. Recife: Editora ASA Pernambuco, 1985.

A questão do território no Brasil. 2 ed. São Paulo: Hucitec, 2004.

AZERÊDO, Robério. Itiúba e os roteiros do padre Severo. Goiânia: Unigraf, 1987.

BARROS, Lícia Margarida Senna Borges de; SENNA, Arlindo Braga. Homem rural nordestino: proposta para seu desenvolvimento. Salvador: Centro Editorial de Didática da UFBA, 1989.

BCB. BANCO CENTRAL DO BRASIL. Conversão de Moedas. Disponível em: <http://www4.bcb.gov.br/pec/conversao/conversao.asp>. Acesso em 21 de junho de 2017.

BEZERRA, Evandro. A terra e a irrigação no nordeste. Fortaleza: Imprensa Universitária UFC, 1996.

BRASIL. Lei no 199, de 2015(complementar). Senado Federal. Publicado no Diário do Senado Federal, Brasília, DF, em 08 de abr. de 2015. Disponível em: <http://legis.senado.leg.br/sdleggetter/documento?dm=3550995\&disposition=inline $>$. Acesso em 03 de agosto de 2017.

BURSZTYN, Maciel. O poder dos Donos: Planejamento e Clientelismo no Nordeste. Petrópolis: Vozes, 1984.

CARVALHO, Inaiá Maria Moreira de. O Nordeste e o regime autoritário: discurso e prática do planejamento regional. São Paulo: Hucitec; [s. 1]: SUDENE, 1987.

CASTRO, Josué de. Sete palmos de terra e um caixão: ensaio sobre uma área explosiva do Nordeste. São Paulo: Editora Brasiliense, 1965. 
CPE. CENTRO DE PLANEJAMENTO E ESTUDOS. Irrigação na Bahia: levantamento dos projetos: Salvador, 1982.

CUNHA, Euclides da. Os sertões. São Paulo: Laemmert, 1902.

DANTAS, José; GONZAGA Luiz. Vozes da seca. In: GONZAGA, Luiz. Luiz Gonzaga canta seus sucessos com Zé Dantas. [S.I.]: RCA/BMG, 1959.1 disco sonoro. Lado B, faixa 03.

DNOCS. DEPARTAMENTO NACIONAL DE OBRAS CONTRAS AS SECAS. Mapa de alguns dos principais açudes do DNOCS. Disponível em:

$<$ http://www.dnocs.gov.br/mapa/acudes.php>. Acesso em 25 de fevereiro de 2017a.

Açude de Cocorobó. Disponível em:

<http://www.dnocs.gov.br/barragens/cocorobo/cocorobo.htm>. Acesso em 25 de fevereiro de $2017 \mathrm{~b}$.

Açude Jacurici. Disponível em:

<http://www.dnocs.gov.br/ dnocs/doc/canais/barragens/Barragem\%20da\%20Bahia/jacurici.ht.> Acesso em 19 de setembro de 2017c.

Perímetro Irrigado Jacurici. Disponível em:

<http://www.dnocs.gov.br/ dnocs/doc/canais/perimetros_irrigados/ba/jacurici.htm>. Acesso em 10 de junho de $2017 d$.

EVANGELISTA, Francisco Raimundo; VIDAL, Maria de Fátima. Irrigação na área de atuação do Banco do Nordeste do Brasil. Escritório Técnico de Estudos Econômico do Nordeste (ETENE), 2012.

FEE. FUNDAÇÃO DE ECONOMIA E ESTATÍSTICA. Atualização de valores. Disponível em: $<$ http://www.fee.rs.gov.br/servicos/atualizacao-valores/>. Acesso em 21 de junho de 2017.

FERNANDES, Carlos et al. Irrigação no Brasil: Situações e Diretrizes. Del Giudice Acessoria Técnica LTDA: Brasília, 2008.

FURTADO, Celso. A fantasia desfeita. Rio de Janeiro: Paz e Terra, 1989.

GOMES, Gustavo Maia. A política de irrigação no Nordeste: intenções e resultados. Pesquisa e Planejamento Econômico, Rio de Janeiro, 9 (2), 411- 446, setembro de 1979. Disponível em: < http://ppe.ipea.gov.br/index.php/ppe/article/viewFile/525/468>. Acesso em 10 de junho de 2017.

GUERRA, Paulo de Brito. A civilização da seca: Fortaleza: DNOCS, 1981.

IBGE. INSTUTO BRASILEIRO DE GEOGRAFIA E ESTATÍSTICA. Itiúba-síntese do município. Disponível em: <http://www.cidades.ibge.gov.br/v3/cidades/municipio/2917003>. Acesso em 05 de janeiro de 2018.

Sinopse do Censo Demográfico 2010: Disponível em:

<https://censo2010.ibge.gov.br/sinopse/index.php?dados=8>. Acesso em 05 de novembro de 2017.

MELLO, Flávio Miguez de. Um século de obras contra as secas. In: MELLO, Flávio Miguez de et al. Cinquenta anos do Comitê Brasileiro de Barragens. Rio de Janeiro: CBDB, 2011.

MENDONÇA, José Ricardo Nunes. Do oásis à miragem: uma trajetória do perímetro irrigado de Sumé - PB no contexto das políticas de desenvolvimento do Nordeste. Dissertação (Mestrado em Ciências Sociais) - Universidade Federal de Campina Grande: Campina Grande 2010.

MI. MINISTÉRIO DA INTEGRAÇÃO NACIONAL. Nova delimitação do semiárido. Brasília: MI, 2005, 32 p. Disponível em:

<http://www.integracao.gov.br/c/document_library/get_file?uuid=0aa2b9b5-aa4d-4b55-a6e182faf0762763\&groupld=24915 >. Acesso em 28 de dezembro de 2017.

NIMER, Edmon. Climatologia do Brasil. $2^{\mathrm{a}}$ ed. Rio de Janeiro: IBGE - Departamento de Recursos Naturais e Recursos ambientais, 1989.

OLIVEIRA, Francisco de. Uma elegia para uma re (li) gião. Rio de Janeiro: Paz e Terra, 1977.

$\begin{array}{lllll}\text { Caminhos de Geografia } & \text { Uberlândia-MG } & \text { v. 20, n. } 70 & \text { Junho/2019 } & \text { p. 385-397 Página } 396\end{array}$


PÉBAYLE, Raymond. Brésil: L'Irrigation Dans le Nordeste, in Problemès d'Amérique Latine, $\mathrm{n}^{\circ}$ 59, $1^{\circ}$ trimester, Paris, 1981.

POMPONET, André Silva. 100 anos de DNOCS: marchas e contramarchas da convivência com as secas. Conj. \& Plan, Salvador, n.162, p.58 - 65, jan./mar. 2009.

QUEIROZ, Raquel de. O quinze. 22ª ed. Rio de Janeiro: J. Olympio, 1977.

RAMOS, Graciliano. Vidas Secas. Rio de Janeiro: J. Olympio, 1938.

RIOS, Kênia Souza. Isolamento e Poder: Fortaleza e os campos de concentração da seca de 1932. Fortaleza: Imprensa Universitária, 2014.

SUDENE. SUPERINTENDÊNCIA DE DESENVOLVIMENTO DO NORDESTE. Delimitação do Semiárido. Disponível em: <http://sudene.gov.br/planejamento-regional/delimitacao-dosemiarido>. Acesso em 28 de dezembro de 2017.

SEI. SUPERINTENDENCIA DE ESTUDOS ECONÔMICOS E SOCIAIS DA BAHIA. Indicadores-municipais-Itiúba. Disponível em:

http://www.sei.ba.gov.br/site/resumos/indicadores/indicadores_2917003.pdf. Acesso em 05 de janeiro de 2016.

SOUZA. Marcelo José Lopes de. O território: sobre espaço e poder, autonomia e desenvolvimento. In: CASTRO; GOMES; CORRÊA (org). Geografia: conceitos e temas. 14 ed. Rio de Janeiro: Bertrand Brasil, 2011.

WARING, Geraldo A. Suprimento de água no Nordeste do Brasil. Rio de Janeiro: sn., 1923

VILLA, Marco Antônio. Vida e Morte no Sertão: história das secas nos séculos XIX e XX. São Paulo: Ática, 2000.

Recebido em: 01/08/2018

Aceito para publicação em: 21/12/2018 